Hugo Pinto de Almeida ${ }^{\mathrm{a}}$

(iD) https://orcid.org/0000-0002-7531-793X

Kátia Reis Souzab

(iD) https://orcid.org/0000-0002-2084-2606

Jose Augusto Pina ${ }^{\mathrm{b}}$

(iD) https://orcid.org/0000-0003-3204-2240

a Ministério da Saúde. Hospital Federal do Andaraí. Rio de Janeiro, RJ, Brasil

${ }^{\text {b}}$ Fundação Oswaldo Cruz, Centro de Estudos da Saúde do Trabalhador e Ecologia Humana. Rio de Janeiro, RJ, Brasil.

Contato:

Hugo Pinto de Almeida

E-mail:

hugopa_rj@yahoo.com.br

Os autores declaram que o trabalho não foi subvencionado e que não há conflitos de interesses.

Os autores informam que o trabalho não foi apresentado em reunião científica.

Trabalho fundamentado na dissertação

"Tudo não é por acaso": exploração, greves, sindicatos surpreendidos e a saúde dos trabalhadores do Complexo Petroquímico do Rio de Janeiro, de Hugo Pinto de Almeida, defendida em 2016 na Escola Nacional de Saúde Pública, Fundação Oswaldo Cruz.

\section{Trabalho e saúde nas lutas dos operários da construção civil do Complexo Petroquímico do Rio de Janeiro}

\author{
Work and Health in the struggles of the construction workers of \\ Rio de Janeiro Petrochemical Complex
}

\section{Resumo}

Introdução: o Complexo Petroquímico do Rio de Janeiro (Comperj) é uma das maiores obras da construção civil pesada no Brasil. A obra constitui-se em cenário de lutas operárias que expressam conflitos das relações de trabalho com implicações na saúde dos trabalhadores. Objetivo: analisar o trabalho e a saúde dos operários da construção civil do Comperj a partir da perspectiva dos trabalhadores, tendo por referência suas lutas e greves. Métodos: pesquisa social de caráter qualitativo com observação participante, levantamento documental e entrevistas com trabalhadores e dirigentes sindicais. Resultados: as práticas de exploração constatadas nos canteiros de obras foram analisadas sob três categorias: terceirização e a saúde dos trabalhadores, prolongamento do tempo de trabalho e gestão por estresse. Conclusão: considerados em conjunto, os resultados representam uma contínua imposição de agravos à saúde dos trabalhadores da construção civil. Nesse contexto, a luta coletiva dos trabalhadores constitui uma condição básica para a proteção à saúde dos trabalhadores.

Palavras-chave: construção civil; intensificação do trabalho; prolongamento do tempo de trabalho; saúde do trabalhador; terceirização.

\begin{abstract}
Introduction: Rio de Janeiro Petrochemical Complex (Comperj) is one of the largest heavy construction in Brazil. It has constituted a scenario of workers' struggles that express conflicts of labor relations with implications on workers' health. Objective: to analyze the work and health of Comperj's construction workers from their perspective, adopting as reference their struggles and strikes. Methods: qualitative social research with participant observation, documentary survey and workers and union leaders' interviews. Results: the exploration practices observed in the workplaces were analyzed in three categories: outsourcing and workers' health, extension of working time and management by stress. Conclusion: taken together, the results represent a continuous imposition of damages on the construction workers' health. In this context, the workers' collective struggle constitutes a basic condition for the protection of workers' health.
\end{abstract}

Keywords: civil construction; work intensification; extension of working hours; occupational health; outsourcing. 


\section{Introdução}

O setor da construção civil (CC) é considerado um dos processos laborais mais precários e perigosos do mundo. No Brasil, tem sido um dos ramos de atividade econômica de maior risco de acidentes fatais e não fatais ${ }^{1}$.

Nos anos 2000, observa-se um novo ciclo de grandes obras da CC no país impulsionado pelo Estado, especialmente com o lançamento em 2007, pelo governo federal, do Programa de Aceleração do Crescimento (PAC). Nesse período cresceu o número de trabalhadores na CC e, ao mesmo tempo, o número total de acidentes de trabalho (AT) no setor, com aumento de aproximadamente $116 \%$, entre 2006 e 2012. Também aumentou a participação relativa dos AT do setor no total no país: de 6,9\%, em 2008, para $8,9 \%$, em $2012^{2}$. Soma-se a isso a grande quantidade de AT fatais que não figuram nos sistemas oficiais de registro ${ }^{3}$.

Segundo Filgueiras ${ }^{4}$, Santana e Oliveira ${ }^{1}$, o crescimento dos índices de mortalidade por AT na CC acontece, precisamente, com a expansão da terceirização no setor. Essa forma de gestão da força de trabalho se caracteriza por práticas de redução de custos, como subcontratações, deixando os operários em condições cada vez mais vulneráveis e socialmente desprotegidos ${ }^{4}$.

Considerada uma das maiores obras da CC pesada no país, a obra do Complexo Petroquímico do Rio de Janeiro (Comperj) mobiliza dezenas de milhares de trabalhadores, especialmente migrantes, gerando impactos sociais, ambientais e de saúde $^{5}$. Contudo, o ponto que se quer realçar diz respeito ao fato do Comperj constituir-se como cenário de lutas operárias, sendo digna de referência, em especial, a greve de 2014 com duração de 64 dias, que expressou o questionamento sobre a situação de trabalho como conflitos entre a base de trabalhadores e a direção sindical.

De fato, a configuração do trabalho em diferentes obras do PAC levou a uma série de reações dos trabalhadores contra a precarização das condições de trabalho, baixos salários e exaustivas jornadas ${ }^{6,7}$. No entanto, verifica-se uma baixa produção de conhecimento relacionada às grandes obras da CC e uma ausência de estudos em relação às obras do Comperj, no que se refere à saúde dos trabalhadores.

Assim sendo, este estudo tem por objetivo analisar o trabalho e a saúde dos trabalhadores da CC do Comperj, sob a perspectiva dos próprios trabalhadores. A reflexão sobre o modo como os trabalhadores percebem o trabalho e a saúde tem por referência as lutas e greves operárias nas obras do Comperj. Essas experiências possibilitam examinar a exploração do trabalho nos canteiros de obra e suas implicações na saúde dos trabalhadores.

\section{Métodos}

Este estudo filia-se à vertente da medicina social latino-americana ${ }^{8}$ e dos estudos operários italianos ${ }^{9}$ que asseguram a importância da produção de conhecimento em saúde junto com coletivos de trabalhadores e suas perspectivas de resistências e de defesa da saúde. Esses trabalhos assinalam que os processos de defesa da saúde dos trabalhadores situam-se no terreno da luta contra a exploração capitalista. Nesse sentido, as experiências de luta dos operários da CC do Comperj podem proporcionar um conhecimento acerca do trabalho e da determinação histórica e social do processo saúde-doença dos trabalhadores.

O Comperj ocupa uma área física de $45 \mathrm{~km}^{2}$ concentrada no município de Itaboraí, região metropolitana do Rio de Janeiro. A obra foi apresentada publicamente como um "eldorado" de oportunidades para os trabalhadores pela quantidade de empregos e ganhos salariais ${ }^{10}$. No auge, empregou até $30 \mathrm{mil}$ trabalhadores, a maior parte migrantes denominados "corre-trecho", operários que percorrem várias obras da CC pelas regiões do país em busca de trabalho. Marx $^{11}$, ao ilustrar a lei geral da acumulação capitalista, caracteriza esse segmento da população trabalhadora como parte da "infantaria ligeira do capital" (p. 224), lançada de uma região a outra conforme a conveniência do capitalista.

No que tange à caracterização da pesquisa e aos procedimentos do estudo, realizou-se uma pesquisa social, lançando-se mão da combinação de abordagens e técnicas de investigação de caráter qualitativo: observação participante, entrevistas individuais com informantes-chave e levantamento documental. Os dados foram coletados entre maio de 2014 e setembro de 2015.

A observação participante compreendeu o acompanhamento de audiências públicas, assembleias dos trabalhadores e visita aos sindicatos. Este procedimento de estudo seguiu a vertente metodológica dos estudos participativos, segundo a qual se concebe que o pesquisador deve estar diretamente no campo, participando da vida cotidiana dos trabalhadores para observar, compreender e realizar anotações de falas e acontecimentos relacionados ao objeto de estudo ${ }^{12}$.

Em termos concretos, a primeira aproximação com os trabalhadores ocorreu na audiência pública realizada na Câmara Municipal de Niterói/RJ, em maio de 2014. Na ocasião, o encontro com trabalhadores de base e representantes sindicais possibilitou 
a identificação de "informantes-chave" para a etapa das entrevistas, como também facilitou o acesso às assembleias e visitas às entidades sindicais.

As entrevistas com os informantes-chave contaram com perguntas abertas por meio de um roteiro semiestruturado $^{13}$. Realizaram-se dez entrevistas, sendo cinco com trabalhadores da CC do Comperj, quatro com diretores do Sindicato dos Petroleiros do Estado do Rio de Janeiro (Sindipetro-RJ) e uma com um funcionário do Sindicato dos Trabalhadores Empregados nas Empresas de Montagem e Manutenção Industrial da cidade de Itaboraí (Sintramon).

Quanto aos documentos levantados que serviram de base de análise do estudo, lançou-se mão dos textos da Convenção Coletiva de Trabalho de 20122016 e das audiências públicas realizadas na Câmara Municipal de Niterói/RJ e na Assembleia Legislativa do Estado do Rio de Janeiro (Alerj).

No tocante à análise dos dados, recorreu-se a técnica de análise de conteúdo, mais especificamente a análise temática, que, segundo Minayo ${ }^{14}$, trata da identificação dos núcleos de significados em determinado corpo textual. Desse modo, o corpo de análise foi composto pelas anotações do diário de campo (instrumento da observação participante), documentos levantados e materiais transcritos das entrevistas. Foram identificados temas por meio da classificação de excertos, por critério de similaridade, frequência e, ainda, pela sua relevância em relação ao tema estudado. Assim, chegou-se a três temas principais de análise: terceirização e a saúde dos trabalhadores; prolongamento do tempo de trabalho e gestão por estresse.

Este estudo obteve aprovação do Comitê de Ética em Pesquisa da Escola Nacional de Saúde Pública Sérgio Arouca sob o Parecer 1.092.582.

\section{Resultados e Discussão}

\section{Terceirização e a saúde dos trabalhadores}

Uma das principais características da organização do trabalho no canteiro de obras do Comperj é a terceirização. Segundo Marcelino e Cavalcante ${ }^{15}$, a terceirização pode ser definida como a interposição de uma empresa na contratação de trabalhadores para realizar atividades para outra empresa (contratante). Essa definição compreende desde a forma clássica (contratação de empresas para prestação de serviços, como limpeza, alimentação, segurança, transporte, entre outras) até a contratação de empresas do próprio ramo da CC. Quanto a este último aspecto, destaca-se a modalidade designada como "terceirização em cascata”15 (p. 341), em que o consórcio principal, responsável pelo conjunto da obra do Comperj, contrata outras empresas para realização de determinada etapa da obra, e sucessivamente cada uma destas empresas subcontratam outras.

O grande número de consórcios e empresas presentes nas diferentes fases da obra dificulta os próprios sindicalistas informarem seu quantitativo com exatidão.

[...] Variou muito chegou a trinta consórcios, sessenta empresas, não sei agora no final quanto está.

A extensão da terceirização no Comperj favorece a ampliação da taxa de lucro com a redução dos custos com força de trabalho, pela sucessiva transferência ("terceirização em cascata") para uma empresa subcontratada das formas de recrutamento, seleção, contratação, avaliação, demissão dos trabalhadores, enfim pela externalização dos conflitos trabalhistas. Nesse sentido, a terceirização constitui-se como processo inseparável do aumento da exploração capitalista e da precarização do trabalho ${ }^{4,15}$.

Deve-se ter presente, também, que a terceirização produz um cenário de variabilidade de situações acerca da infraestrutura de trabalho e das condições sanitárias dos trabalhadores nos canteiros de obra, já que são empresas diferentes, que operam de formas diversas, mas ocupam o mesmo espaço de trabalho.

O calor total e inclusive de faltar água. Então teve esse problema da infecção intestinal, depois teve o lance da lagartixa encontrada no prato. Depois um trabalhador mastigou um caco de vidro grande e cortou a boca.

[...] a outra [empresa], até comida estragada dava. A nossa não, graças a Deus era muito tranquila.

As precárias condições de alimentação dos operários da CC também são mencionadas por outros estudos em grandes obras realizadas ainda no regime militar brasileiro, como as do metrô na cidade do Rio de Janeiro ${ }^{16}$ e, atualmente, em outras obras do PAC $^{6,7}$.

A situação dos alojamentos dos operários também se constituiu como importante tema advindo nas audiências públicas ${ }^{17}$ e entrevistas com os trabalhadores. Eles relatam que ao chegar a Itaboraí, muitos trabalhadores migrantes eram surpreendidos ao saber da inexistência de alojamentos, então prometido pelo contratante, ou ainda ao receberem a informação de que o alojamento era temporário.

[...] Tinha muita gente que vinha de fora, então, a empresa prometia alojamento e aí depois não cumpria ou o alojamento era temporário, aí depois o cara tinha que se virar [...] 
Segundo os entrevistados, havia empresas que cobravam aluguel pelo alojamento, além disso, os relatos também apontam para a precária condição sanitária desses alojamentos. Quanto a este último aspecto, situações semelhantes foram constatadas em outras obras da CC, relacionando-o à ocorrência de epidemias e surtos de virose, gripes e diarreias ${ }^{6,7}$. Nesse sentido, vale retomar a atualidade da categoria "infantaria ligeira do capital", apresentada por Marx ${ }^{11}$. Segundo a descrição em $O$ Capital, o próprio empresário da obra fornecia o alojamento "[...] sem a menor garantia de higiene, longe do controle das autoridades locais, porém altamente rentáveis para o senhor contratante que deste modo explora seus operários duplamente, como soldados individuais e como inquilinos" (p. 224-225).

Outra consequência importante da terceirização diz respeito à fragmentação dos coletivos de trabalho como o modo de organização das Comissões Interna de Prevenção de Acidentes (Cipa). No Comperj, a representação da Cipa está organizada, igualmente, por empresa. Em que pesem as tentativas de superação do fracionamento dos trabalhadores, por parte do Sindipetro/RJ, por meio da convocação dos cipeiros das empresas terceirizadas para participação nas reuniões da Cipa da Petrobras:

As reuniões de Cipa são feitas só com os membros da Petrobras; o membro de empresa terceirizada simplesmente não aparece. Seja porque a empresa não autoriza a saída dele para participar da Cipa, ou pela falta de interesse da própria Petrobras.

A ausência em reuniões dos representantes das Cipa, pertencente a diferentes empresas terceirizadas, dificultou uma ação sindical mais concreta alusiva ao enfrentamento das condições nocivas à saúde dos trabalhadores.

Verificou-se que, no cotidiano do canteiro de obras, as empresas produzem várias estratégias para ampliar a fragmentação dos trabalhadores. O objetivo dessa ação é dificultar a constituição dos coletivos operários. Os entrevistados citaram alguns desses recursos no momento que são impossibilitados de circular entre os canteiros de obras e manter contato com colegas de outras unidades nos ônibus, refeitórios e nas diferentes 27 Cipa, até mesmo nos serviços de saúde, locais onde poderiam ser ponto de referência para encontro e organização dos trabalhadores com vistas à defesa coletiva da saúde.

Cada um não podia entrar em outra unidade porque você tinha seu setor. A outra firma tinha lá as outras unidades e não podiam sair de um canteiro para outro $[\ldots]$.

Para Linhart ${ }^{18}$, constitui-se como estratégia das empresas criarem mecanismos para que não se desenvolvam redes de cumplicidade e apoio entre os trabalhadores nos ambientes de trabalho. Tomando por base de compreensão as entrevistas de campo, parece acertado afirmar que a luta sindical e dos trabalhadores não caminhou na direção de um enfrentamento direto contra a terceirização, mas sim, a seus diferentes efeitos, que estão dispersos na realidade dos problemas em termos de precarização das condições de trabalho.

\section{Prolongamento do tempo de trabalho}

Partindo-se do pressuposto teórico segundo o qual o prolongamento do tempo de trabalho constitui fundamento da exploração capitalista para extração da mais-valia ${ }^{11}$, organizamos a análise do tempo de trabalho dos operários do Comperj destacando três aspectos, procedentes dos materiais de campo, que configuram o prolongamento da jornada: as horas extras; as horas in itinere e o cancelamento da folga de campo.

Pensando em uma obra de grande magnitude, como no caso do complexo petroquímico, e a presença de variados contratos que regulam diferentes prazos de entrega dos serviços, constatou-se que os distintos consórcios contratados ou empresas subcontratadas, em diversos estágios da obra, utilizaram, continuamente, o mecanismo das horas extras, primeiro aspecto analisado do prolongamento do tempo de trabalho.

No Comperj, os empregados cumprem a jornada semanal de 44 horas, sendo dividida em quatro dias de 9 horas e um dia de 8, com a compensação do sábado. Mas, em lugar de folga, o sábado se converte em dia adicional de trabalho em regime de hora extra. Além do sábado, também era comum a convocação para trabalhar aos domingos e feriados.

Distinguiu-se nos materiais de campo o fato de que a realização de horas extras pelos trabalhadores é exigência por parte das empresas, especialmente para os operários "corre-trecho". Para estes, trabalhar em horário suplementar é condição para manutenção do emprego e possíveis futuras contratações.

[...] Aí quem vem de fora, que está numa condição pior acabava se submetendo.

[...] Eu entrei pela indicação, pois eu conhecia o pessoal aqui. Na verdade, eu já até trabalhei com esse pessoal em São Paulo, tinha vaga e eles chamaram para vir.

De fato, no decurso das entrevistas, confirmou-se uma modalidade de rede de contratação na CC, um arranjo de mercado, no sentido de manter o trabalhador refém para responder sempre afirmativamente à convocação para trabalhar em regime 
de horas extras. Do contrário, caso o trabalhador se recuse, pode ser excluído dessa rede, sofrendo punição como demissão e, ainda, com a não contratação em futuras obras.

O segundo aspecto diz respeito ao tempo despendido pelo trabalhador no deslocamento de ida e retorno ao trabalho em local de difícil acesso ${ }^{19}$, como as obras do Comperj. Esse tempo de deslocamento recebe a denominação de horas in itinere, que integram a jornada de trabalho. O deslocamento dos trabalhadores até a obra é realizado em ônibus fretado pelas empresas. Diariamente, os trabalhadores perfazem 14 horas ou mais de jornada trabalhista: tempo de trabalho no canteiro de obras adicionado ao tempo de deslocamento.

[...] Tem gente que acorda três e meia, quatro horas da manhã, para chegar [...] e retorna muito tarde.

No início das obras do Comperj, as horas in itinere não eram incluídas na jornada de trabalho. Sua inclusão parcial acontece na Convenção Coletiva de Trabalho de $2012^{20}$, como um dos resultados da greve operária daquele ano. A partir de então, as empresas passaram a computar trinta minutos por dia efetivamente trabalhado a título de horas in itinere. Um tempo, diga-se, bem inferior ao efetivamente despendido pelos trabalhadores no deslocamento ao trabalho. Mas, em lugar de redução da jornada, esse tempo é contabilizado e pago a cada trabalhador, conforme seu salário-base.

A outra forma de prolongamento do tempo de trabalho se efetiva por meio do cancelamento da "folga de campo". A folga de campo é um direito dos trabalhadores, em atividades distantes de suas residências, de modo a realizar visitas aos familiares depois de determinado tempo de trabalho. No Comperj, a conquista da folga de campo resulta da greve dos operários de 2013, incluída na Convenção Coletiva de 2013-2014 ${ }^{20}$. Posteriormente, a Convenção Coletiva de 2015-2016 ampliou essa conquista estabelecendo o direito a gozar folga de campo a cada noventa dias ${ }^{20}$. No entanto, segundo relatos dos trabalhadores, as empresas utilizam artifícios para descumprir essa conquista.

Obrigam os trabalhadores a apresentar [...] um comprovante de residência do local [região metropolitana do Rio de Janeiro] e aí não reconhece que eles são de fora.

Com isso, os dias que deveriam ser utilizados, por direito, para partilhar da vida social com familiares e amigos são incorporados na jornada de trabalho, na prática, convertem-se em prolongamento do tempo de trabalho.
Na tentativa de amenizar a distância e a solidão, os operários tentam reproduzir a realidade de suas regiões de origem a partir das músicas, brincadeiras e uso de expressões próprias e gírias. Constata-se que as atividades de socialização aumentam a solidariedade operária, podendo ser interpretadas como estratégias coletivas de enfrentamento do sofrimento ${ }^{18}$.

Na reconstrução da problemática atinente ao tempo de trabalho dos operários do Comperj, verifica-se que o questionamento e a luta dos trabalhadores às exigências de tempo de trabalho suplementar resultaram em conquistas como as horas in itinere e a folga de campo. Mas, as empresas deslocam o sentido do questionamento operário para a negociação da remuneração do tempo de trabalho suplementar. Esse deslocamento pelas empresas é favorecido quando a pauta sindical reproduz reivindicações relativas à compensação monetária em lugar de priorizar a efetiva redução da jornada de trabalho, o que coloca em questão certas práticas do sindicalismo brasileiro ${ }^{21}$.

Ao fim, tratam-se de compensações monetárias do desgaste da força de trabalho. A rigor, o aumento da sobrecarga laboral, pelo prolongamento do tempo de trabalho, gera efeitos nocivos à saúde, conforme asseveram muitos estudos sob os mais diversos ângulos: aumento dos acidentes de trabalho ${ }^{22}$, aparecimento de diferentes doenças ${ }^{23,24}$, problemas psicossociais, incluindo registros de casos de suicídios ${ }^{25}$ e dificuldade para construção de vínculos coletivos entre os trabalhadores ${ }^{18,26}$.

É válido mencionar ainda que as entrevistas chamam atenção para a intensificação do ritmo de trabalho por meio do prolongamento da jornada, sobretudo quando se reduzem os intervalos de descanso intra e interjornadas, respectivamente, ao estender o horário de saída na jornada diária e eliminar o repouso aos sábados, domingos e feriados.

\section{Gestão por estresse}

No canteiro de obras do Comperj, a pressão para o aumento da produtividade dos trabalhadores está explicitada em práticas gerenciais das empresas, caracterizadas como gestão por estresse ${ }^{27}$. Nelas destacam-se dois importantes aspectos: o sistema de metas e o sistema disciplinar de vigilância dos trabalhadores.

O sistema de metas tem como principal característica ser vinculado ao pagamento da participação nos lucros e resultados (PLR), como previsto na convenção coletiva de trabalho. O valor do bônus da PLR está condicionado ao alcance de metas individuais e coletivas sendo aferidas mensalmente ${ }^{20}$. Integram as metas individuais: "advertência", "absenteísmo" e "segurança, meio ambiente e saúde" ${ }^{20}$. A aplicação 
de uma advertência/penalidade acarreta a perda do valor da PLR proporcional ao mês de sua aplicação ${ }^{20}$. Em relação ao absenteísmo, mais de duas faltas sem justificativa no período de um ano acarreta a perda do valor da PLR referente ao mês das faltas.

No caso da meta "segurança, meio ambiente e saúde" aborda, sobretudo, o controle do AT e estabelece o "índice zero de acidentes de trabalho com afastamento" e sua apuração é realizada pela Cipa. $\mathrm{O}$ trabalhador responsabilizado pelo AT perde o valor da PLR referente ao semestre de ocorrência do evento. Trata-se de prática gerencial para imputar culpa ao trabalhador acidentado e eximir de responsabilidade as empresas pelo $\mathrm{AT}^{28}$.

As metas coletivas são estabelecidas em termos de "produção e produtividade" e aferidas por meio de medições específicas ("peso", "medidas" e "solda") por cada tipo de trabalho ${ }^{20}$. Estas metas, como ilustram diferentes trabalhadores, condicionam o ritmo de trabalho no sentido de sua intensificação.

Porque tem a questão da medição e a medição é que fala mais alto. [...] Muita correria para fazer os trabalhos para bater a meta.

A rigor, a aferição mensal das metas representa um instrumento de pressão para extração de mais trabalho com eliminação ou redução da porosidade durante a jornada ${ }^{29}$. As expressões "cobrança", "correria” e "desespero", presentes nas falas operárias, traduzem os sentidos da intensificação do trabalho nas práticas do sistema de metas, comprometendo fortemente o tempo para pausas e descansos durante a jornada.

[...] Tinha que ser mais rápido, acelerar as coisas que na hora e principalmente no final do mês que tinha medição.

A pressão para o alcance das metas individuais e coletivas tenta torná-las de responsabilidade de cada trabalhador ou da equipe de trabalho com o objetivo de difundir a vigilância entre os próprios operários.

Com efeito, ressalta-se a natureza disciplinar incorporada nas metas individuais e coletivas no sentido de constranger o trabalhador a não se afastar do trabalho ou retardar a procura por cuidados de saúde. Fica evidente a forma de violência do sistema de metas em que o afastamento por motivo de saúde aparece como ameaça ao trabalhador pelo receio de sofrer penalidades, como descontos no salário e diminuição no bônus da PLR, passando por advertências até a demissão. Com isso, qualquer impedimento para o desempenho de suas funções, mesmo por motivo de saúde, o trabalhador é pressionado a manter-se no posto de trabalho.
Aí eu fui lá falei que não ia ficar lá não [enfermaria], vou ficar no meu setor de trabalho porque a pressão no meu setor era muito grande e eu tinha que está ali [...] para poder suprir a necessidade da construção civil.

Nas entrevistas realizadas destacou-se o aspecto referente ao presenteísmo ${ }^{30}$. De acordo com Franco, Druck e Seligmann-Silva ${ }^{30}$, trata-se de um fenômeno intrínseco a precarização social do trabalho, em que trabalhadores com problemas de saúde limitantes à sua capacidade laboral não se afastam de suas atividades e, por meio de um sobre-esforço, procuram mantê-las ao mesmo tempo que dissimulam seus males. No presenteísmo se destaca o medo da demissão constatado entre os operários do Comperj e, como mencionamos anteriormente, da exclusão das redes de contratação. Nessa linha de interpretação, mecanismos de defesa psicológica (como o de negação) atuam no sentido de impedir os próprios trabalhadores a estabelecer distinções dos agravos à saúde sofridos no trabalho . Por conseguinte, em muitos casos, os processos de adoecimento evoluem, tornam-se crônicos e aprofundam sua gravidade.

Destacam-se, ainda, medidas disciplinares na tentativa de impedir a circulação dos operários entre os canteiros da obra, como a utilização de uniformes com cores diferentes por empresa; o vasto uso de equipamentos eletrônicos como celulares e câmeras, além da presença de seguranças ("vigias"). Os relatos também apontam o emprego de drones nos locais de trabalho, tecnologia originalmente projetada para objetivos militares:

Hoje, se você for ao Comperj, você vai ver que tem câmera a trinta metros de altura e tem até drone [...]. Quando olho para o lado, tem um drone me filmando e filmando os caras. Aí eu falei: 'se colocar isso aqui de novo vou trazer uma atiradeira e vou acertar o drone'.

Com base nos depoimentos dos trabalhadores, a utilização do estresse como instrumento de gestão nos canteiros de obra do Comperj está marcada por forte disciplina e hierarquia, que estrutura e orienta o sistema de metas. A gestão por estresse acentua a tendência para revogar as mais elementares medidas de proteção à saúde e à vida dos trabalhadores.

Nessa correria que era complicado porque, às vezes, começava a chover e aí caia o raio e você tinha que parar, mas a sirene não tocava. [...] Independente do coordenador ou supervisão de solda, eu mandava parar e falava no rádio.

Embora os relatos exprimam formas de resistência operária no confronto à pressão pela produtividade no canteiro de obras, esta resistência ainda permanece difusa, uma vez que não é vocalizada 
pela ação sindical dos trabalhadores no questionamento a vinculação da PLR ao sistema de metas. O estudo constatou a ausência de uma perspectiva sindical crítica da PLR enquanto instrumento de intensificação da exploração do trabalho.

\section{Considerações finais}

A partir da luta dos trabalhadores, foi possível conhecer algumas dimensões do trabalho e da saúde dos operários da CC nas obras do Comperj: terceirização, longas e extenuantes jornadas, gestão por estresse, intensificação do trabalho, disciplina rígida e precária situação sanitária que proporcionam uma contínua imposição de agravos à saúde dos trabalhadores.

Nesse contexto, o confronto operário à exploração constitui a principal condição para a proteção à saúde dos trabalhadores. Observa-se que nas greves foram constatadas diferenças de perspectivas entre a representação sindical e a comissão composta pelos trabalhadores de base. Mas, não foi nosso propósito analisá-la neste artigo.

A dimensão coletiva na luta dos trabalhadores pela saúde emerge desse estudo como um problema de pesquisa. Com isso, este estudo reafirma a importância da produção de conhecimento a respeito da luta coletiva dos trabalhadores, enquanto um dos pressupostos constitutivos da Medicina Social Latino-Americana e da Saúde do Trabalhador, sobre a perspectiva dos próprios operários.

Finalmente é válido mencionar que a sanção da Lei 13.429/2017, sobre a terceirização, e a vigência da reforma trabalhista (Lei 13.467/2017) com a prevalência do acordado sobre o legislado ampliam ainda mais a relevância da organização dos trabalhadores nos locais de trabalho, tema caro à trajetória da Saúde do Trabalhador, mas ainda pouco abordado pelas pesquisas nesta área de conhecimento.

\section{Contribuições de autoria}

Almeida, HP foi responsável pelo desenho do projeto, revisão bibliográfica, coleta, análise e interpretação dos dados. Souza, KR e Pina, JA foram responsáveis pelo desenho do projeto, revisão bibliográfica, análise e interpretação, desenvolvimento do manuscrito e aprovação final da versão publicada.

\section{Referências}

1. Santana VS, Oliveira RP. Saúde e trabalho na construção civil em uma área urbana do Brasil. Cad Saúde Pública. 2004;20(3):797-811.

2. Pereira ES. Análise das estatísticas de acidentes de trabalho na construção civil. Informe de Previdência Social. 2014;26(7):3-16.

3. Mangas RMN, Gómez CM, Thedim-Costa SMF. Acidentes de trabalho fatais e desproteção social na indústria da construção civil do Rio de Janeiro. Rev Bras Saúde Ocupacional. 2008;33(118):48-55.

4. Filgueiras VA. Terceirização e acidentes de trabalho na construção civil [Internet]. 2016 [acesso em 2016 fev 9]. Disponível em: http://www.ihu. unisinos.br/541982-terceirizacao-e-acidentes-detrabalho-na-construcao-civil

5. Toledo LM, Sabroza PC. Síntese anual 2010. Plano de monitoramento epidemiológico do processo de implantação do Comperj. Monitoramento da evolução das causas relevantes de adoecimento e morte nos municípios de Itaboraí, Guapimirim e Cachoeiras de Macacú: a situação epidemiológica. Rio de Janeiro: Fiocruz/ENSP; 2011.

6. Véras R. Brasil em obras, peões em luta, sindicatos surpreendidos. Rev Crítica Ciênc Sociais. 2014;1(103):111-36.
7. Conceição T. Trabalhadores no canteiro de obras da UHE de Belo Monte-Altamira: condições de saúde e políticas públicas [dissertação]. Belém (PA): Universidade Federal do Pará; 2014.

8. Laurell AC, Noriega M. Processo de produção e saúde: trabalho e desgaste operário. São Paulo: Hucitec; 1989

9. Oddone I, Marri G, Gloria S. Ambiente de trabalho: a luta dos trabalhadores pela saúde. São Paulo: Hucitec; 1986

10. Alencar E, Galdo R. Trinta mil operários de vários estados do país "correm trecho" em busca do tesouro. O Globo. 2014 jun 4;17.

11. Marx K. O capital: crítica da economia política. 2nd ed. São Paulo: Nova Cultural; 1985. (vol. 1).

12. Brandão CR. Reflexões sobre como fazer trabalho de campo. Soc Cult. 2007;10(1)11-27.

13. Bisol CA. Estratégias de pesquisa em contextos de diversidade cultural: entrevistas de listagem livre, entrevistas com informantes-chave e grupos focais. Estud Psicol Camp. 2012;29:719-26.

14. Minayo MCS. O desafio do conhecimento. São Paulo: Rio de Janeiro: Hucitec; Abrasco; 1992. 269 p. 
15. Marcelino P, Cavalcante S. Por uma definição de terceirização. Cad CRH. 2012;25(65):331-46.

16. Valladares LP. Quebra-quebras na construção civil: o caso dos operários do metro do Rio de Janeiro. Ciênc Sociais Hoje Mov Sociais Urbanos Minor Étnicas Outros Estud. 1983;113-43.

17. Assembleia Legislativa do Rio de Janeiro (Alerj). Discutir a precarização do trabalho no Comperj. Sect. Comissão de Trabalho, Legislação Social e Seguridade Social Assembleia Legislativa do Rio de Janeiro; 2014 mar 27;88.

18. Linhart D. Entrevista: Danièle Linhart. Trab Educ Saúde. 2011;9(1):149-60.

19. Brasil. Lei $\mathrm{n}^{\mathrm{O}} 10243$ [Internet]. 2001 jun 19 [acesso em 2017 fev 21]. Disponível em: http://www. planalto.gov.br/ccivil_03/leis/LEIS_2001/L10243. htm

20. Sindicato dos Trabalhadores Empregados nas Empresas de Montagem e Manutenção Industrial da cidade de Itaboraí; Sindicato das Empresas de Montagem e Manutenção do Complexo Petroquímico do Rio de Janeiro. Convenção Coletiva de Trabalho 2012-2016. Rio de Janeiro: Sintramon; 2016.

21. Pina JA, Stotz EN. Intensificação do trabalho e saúde dos trabalhadores: um estudo na Mercedes Benz do Brasil, São Bernardo do Campo, São Paulo. Saúde Soc. 2015;24(3):826-40.

22. Caruso CC, Hitchcock EM, Dick RB, Russo JM, Schmit JM. Overtime and extended work shifts: Recent findings on illnesses, injuries, and health behaviors. Ohio: U.S. Department of Health and Human Services; 2004.

23. Ribeiro HP, Lacaz FAC. De que adoecem e morrem os trabalhadores? São Paulo: Departamento Intersindical de Estudos e Pesquisas de Saúde e dos Ambientes de Trabalho (DIESAT); 1984.

24. Van der Hulst M. Long workhours and health. Scand J Work Environ Health. 2003;29(3):171-88.

25. Hirata H. Tendências recentes da precarização social e do trabalho: Brasil, França, Japão. Cad CRH. 2011;24(spe 1):15-22.

26. Araújo AJS. Paradoxos da modernização: terceirização e segurança em refinaria de petróleo [tese]. Rio de Janeiro: Escola Nacional de Saúde Pública; 2001.

27. Parker M, Slaughter J. Unions and management by stress. In: Babson S. Lean work: empowerment and exploitation in the global auto industry. Detroit: Wayne State University Press; 1995. p. 41-53.

28. Vilela RAG, Iguti AM, Almeida IM. Culpa da vítima: um modelo para perpetuar a impunidade nos acidentes do trabalho. Cad Saúde Pública [online]. 2004;20(2):570-9.

29. Pina JA, Stotz EN. Participação nos lucros ou resultados e banco de horas: intensidade do trabalho e desgaste operário. Rev Bras Saúde Ocupacional. 2011;36(123):162-76.

30. Franco T, Druck G, Seligmann-Silva E. As novas relações de trabalho, o desgaste mental do trabalhador e os transtornos mentais no trabalho precarizado. Rev Bras Saúde Ocupacional. 2010;35(122):229-48. 